\title{
Ultrasonography as a Modern Teaching Support to the Anatomy Course: Is It Beneficial for Medical Students?
}

About the Author: Hanna Garnier, Pawel Plosaj and Jakub Wisniewski are currently final-year medical students in a six-year program at the Medical University of Gdansk, Gdansk, Poland. They are members of the Pediatric Surgery and Urology Students' Scientific Association at the Medical University of Gdansk.

Submission: Apr 4, 2015 Acceptance: May 7, 2015 Publication: Jun 7, 2015

\section{To the Editor,}

The approach to evaluating anatomy teaching effectiveness has changed over time (from ancient Egypt through Baroque to modern times). ${ }^{1,2}$ In the 2oth century, medical schools started to use first radiological images, such as roentgen images, during anatomy classes. ${ }^{3}$ Nowadays, computed tomographs, magnetic resonance images and ultrasonography are also widely used. ${ }^{4}$ At Mount Sinai School of Medicine in New York, new didactic methods, which included minimally invasive approaches, radiological imaging and plastinated prosections, are incorporated into anatomy courses for medical students. ${ }^{5}$ However, we should keep in mind that undergraduate medical curriculum, especially during the first year, is already overcrowded. Thus, every new supportive teaching method must have its efficacy carefully analyzed and scientifically proven before being introduced into medical schools.

Ultrasonography (US) is a cheap, easy-to-reach and safe supplement to the anatomy course. US practical classes can facilitate understanding of topographic anatomy. Students need to know the exact location of each anatomical structure in order to retrieve a proper US image.

In 2006, Rao and colleagues conducted a pilot study of integrating US curriculum into the first-year medical programme at the Wayne State University School of Medicine. ${ }^{6}$ They reported many advantages of their US courses, which pay special heed to the importance of knowing the basic US rules during the first year of studies. Subsequently, in 2014, Dreher and colleagues, in their research conducted on 269 first year medical students, proved that ultrasonography can be a valuable supplement to the musculoskeletal, thoracic, abdominal and neck anatomy lessons.7 They showed, on the basis of pre- and post-lesson surveys, that students significantly improved self-confidence with regard to their anatomical knowledge. Additionally, students were able to perform a basic US examination on their own following course completion.

Many works concerning the usefulness of US in teaching anatomy were conducted on the basis of questionnaires. ${ }^{8-11}$ All of them reported positive evaluations of the US classes by the students, although none of them compared the results of their studies with a control group. The only study trying to examine the positive influence of US on anatomy classes using a comparison group was performed by Knobe and colleagues in $2012 .^{12}$ They proved that ultrasonography has a better effect on the understanding of anatomy compared to arthroscopy.

Based on the aforementioned studies, it seems that anatomy learning should be based not only on dissections, but also on complementary methods, such as US. It should be emphasized that works which have been published thus far concern only subjective opinions of the students. To reach definitive conclusions, long-term randomized controlled studies are needed in order to objectively compare US education with other learning modalities and obtain unambiguous results.
Hanna Garnier,' Pawel Plosaj,, Jakub Wisniewski. ${ }^{\text {' }}$
'Faculty of Medicine. Medical University of Gdansk. garnierhanna@gmail.com

\section{References}

1. Nunn JF. Ancient Egyptian medicine. Norman: University of Oklahoma Press; 1996.

2. Schupbach W. The paradox of Rembrandt's 'Anatomy of Dr. Tulp'. Med Hist Suppl. 1982;(2):1-110.

3. Pabst R, Westermann J, Lippert H. Integration of clinical problems in teaching gross anatomy: living anatomy, $\mathrm{X}$-ray anatomy, patient presentations, and films depicting clinical problems. Anat Rec. 1986 May;215(1):92-4.

4. Erinjeri JP, Bhalla S. Redefining radiology education for first-year medical students: shifting from a passive to an active case-based approach. Acad Radiol. 2006 Jun;13(6):789-96.

5. Reidenberg JS, Laitman JT. The new face of gross anatomy. Anat Rec. 2002 Apr 15;269(2):81-8.

6. Rao S, van Holsbeeck L, Musial JL, Parker A, Bouffard JA, Bridge P, et al. A pilot study of comprehensive ultrasound education at the Wayne State University School of Medicine: a pioneer year review. J Ultrasound Med. 2008 May;27(5):745-9.

7. Dreher SM, DePhilip R, Bahner D. Ultrasound exposure during gross anatomy. J Emerg Med. 2014 Feb;46(2):231-40.

8. Swamy M, Searle RF. Anatomy teaching with portable ultrasound to medical students. BMC Med Educ. 2012 Oct 22;12:99.

9. Stringer MD, Duncan LJ, Samalia L. Using real-time ultrasound to teach living anatomy: an alternative model for large classes. N Z Med J. 2012 Sep 7;125(1361):37-45.

10. Mircea PA, Badea R, Fodor D, Buzoianu AD. Using ultrasonography as a teaching support tool in undergraduate medical education - time to reach a decision. Med Ultrason. 2012 Sep;14(3):211-6.

11. Tutarel O, Luedemann W, Nautrup CP, Jahn K, Wilke M, Berens von Rautenfeld $\mathrm{D}$. Introduction and evaluation of a modular seminar system in gross anatomy teaching at the Hannover Medical School. Ann Anat. 2000 Jul; $182(4): 393-6$

12. Knobe M, Carow JB, Ruesseler M, Leu BM, Simon M, Beckers SK, et al. Arthroscopy or ultrasound in undergraduate anatomy education: a randomized cross-over controlled trial. BMC Med Educ. 2012 Sep 9:12:85.

Acknowledgments: We thank Wolf Lüdemann from the Department of Neurosurgery, International Neuroscience Institute in Hannover, Germany for sharing his publication.

Conflict of Interest Statement at Funding: The Author has no funding, financial relationships or conflicts of interest to disclose.

Author Contributions: Conception and design the work/idea, Write the manuscript, Critical revision of the manuscript, Approval of the final version: $\mathrm{HG}, \mathrm{PP}, \mathrm{JW}$.

Cite as: Garnier H, Plosaj P, Wisniewski J. Ultrasonography as a Modern Teaching Support to the Anatomy Course: Is It Beneficial for Medical Students?. Int J Med Students. 2015 Apr-Aug;3(2):119. 